\title{
Research Paper: Satisfaction and Competence With Telepractice Services in Pakistan Amid COVID-19 Pandemic: The Speech-Language Pathologists' Perspective
}

\author{
Sidra Akram¹ (D), Nazia Mumtaz², Nameeka Shahid ${ }^{3}$ (iD, Ghulam Saqulain ${ }^{4 *}$ (i) \\ 1. Department of Speech Language Pathology, Riphah International University, Islamabad, Pakistan. \\ 2. Department of Speech Language Pathology, Faculty of Rehab \& Allied Health Sciences, Riphah International University, Islamabad. \\ 3. Department of Speech Language Pathology, Riphah Inernational university, Lahore, Pakistan. \\ 4. Department of Otorhinolaryngology Capital Hospital PGMI, Shaheed Zulfiqar Ali Bhutto Medical University, Islamabad, Pakistan.
}

\begin{tabular}{|l|l|l}
\hline $\begin{array}{c}\text { Use yur devic to scan } \\
\text { and read the article online }\end{array}$ & $\begin{array}{l}\text { Aftation: Akram S, Mumtaz N, Shahid N, Saqulain G. Satisfaction and Competence With Telepractice Services in Pakistan } \\
\text { Amid COVID-19 Pandemic: The Speech-Language Pathologists' Perspective. Iranian Rehabilitation Journal. 2021; 19(3):251- } \\
\text { 260. http://dx.doi.org/10.32598/irj.19.3.1335.3. }\end{array}$ \\
dointtp://dx.doi.org/10.32598/irj.19.3.1335.3
\end{tabular}

\section{Article info:}

Received: 02 May 2021

Accepted: 27 Jul 2021

Available Online: 01 Sep 2021

Keywords:

Competence and satisfaction, COVID-19, Telepractice, Telehealth, Speech-language pathology

\section{ABSTRACT}

Objectives: This study aimed to explore satisfaction and competency with telepractice services among Speech-Language Pathologists (SLPs) in Pakistan.

Methods: This cross-sectional study with a sample of 204 SLPs was conducted at Riphah International University, Lahore Campus, Lahore, Pakistan, from August 2020 to December 2020. Our study recruited qualified SLPs of both genders, aged between 25 and 60 years, using a convenience sampling technique. Non-practicing SLPs and those holding administrative posts were excluded from this study. The "Service Provider Questionnaire for Telepractice" was used for data collection. The obtained data were analyzed in SPSS v. 22. The Chi-square and Pearson $r$ correlation were used to detect any relationships between study variables, and $\mathrm{P}<0.05$ was significant.

Results: The results showed that SLPs are pretty satisfied with using telepractice and building relationships with child/family, compared to face-to-face practice, and did not reveal significant differences $(\mathrm{P}=0.146$ and $\mathrm{P}=0.882$, respectively). Also, the competence of SLPs was good with telepractice; however, higher competence was noted with face-to-face practice, and the difference was statistically significant $(\mathrm{r}=0.165, \mathrm{P}=0.018)$.

Discussion: Regarding satisfaction with the use of telepractice and relationship building with child/family, SLPs are pretty satisfied, though results did not differ significantly from face-toface practice. However, for competence in providing services, the SLPs felt more competent with face-to-face practice than telepractice. Satisfaction using telepractice has an association with patient's age and SLP's experience and age, while satisfaction with relationships using telepractice is associated with SLP's qualification and experience. Competence in providing telepractice is associated with patient's age and SLP'S qualification, experience, and age.

\section{* Corresponding Author:}

Ghulam Saqulain, DLO., FCPS.

Address: Department of Otorhinolaryngology Capital Hospital PGMI, Shaheed Zulfiqar Ali Bhutto Medical University, Islamabad, Pakistan. Tel: +98 (33) 35101134

E-mail: ghulam_saqulain@yahoo.com 


\section{Highlights}

- Speech-Language Pathologists (SLPs) seem satisfied with telepractice and relationship building with child/family using telepractice at par with face-to-face practice.

- SLPs are competent in using telepractice.

- Satisfaction and competence with telepractice are also associated with patient's age, SLP's age, and experience.

- Satisfaction with building relationships with telepractice is associated with qualification and experience of SLP.

\section{Plain Language Summary}

COVID-19 pandemic has forced many countries like Pakistan with a weak health care system to opt for online service provision. Telehealth is not a new concept, yet its use by SLPs is a comparatively novel area of research, where SLPs have started providing rehabilitation services via telepractice, with a dearth of literature in the field. In this study, SLPs' satisfaction and competence with telepractice were explored. According to the results, SLPs' satisfaction using telepractice and relationship building with child/family had no significant difference from face-to-face practice. However, the SLPs felt more competent with face-to-face practice. This study can address the significant gap of research for the provision of SLPs services in society. The results help provide and improve their services for patients in remote areas who lack access to these services due to long distances, logistics, and other pertinent reasons. These people will benefit from telepractice sessions along with significant others in the geriatric population with compromised mobility as well.

\section{Introduction}

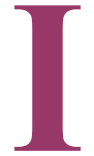

nfectious diseases are on the rise, and with the recent COVID-19 pandemic, even developing countries like Pakistan, with a weak and struggling health care system, have been forced to opt for online learning, teaching, and providing services [1]. Fears of picking and spreading disease have made telepractice a therapeutic window for the present and future [2]. American Speech Language Hearing Association (ASHA) has defined telepractice as "the implication of telecommunication technology to pass on professional services far away by connecting clinician to client, or clinician to clinician for assessment, referrals, treatment or discourse" [3]. Instead of telehealth, the word used for the provision of medical management far away from the provider, ASHA has advocated the use of the word "telepractice" for service provided by speech-language pathologists (SLPs) in far-flung areas [4]. In this new modality, SLPs' servicing therapy are under scrutiny for ethical and legal issues of the profession [5].

Keeping in view the global discrepancy of patient-clinician ratio, the SLPs scarcity is felt now and then because $24 \%$ of SLPs in private settings reported insufficient numbers to fill the slots, requiring telepractice to bridge the gap [6]. The use of telecommunication strategy in healthcare management is not new, yet its implementation for SLPs is a new era [7]. Brown J. revealed that SLPs and audiologists began administering telepractice in the United States and other developed nations through different settings on clients of varying ages, using different provider services and communication capacities [8].

Today, teletherapy is a synchronous facility, which is administered instantaneously with an active audible and visible link like face-to-face interaction [9]. It is equally valuable for extending speech therapy services to the impoverished, who need these services but do not have access to clinicians [10] or live far away. Fear of contracting diseases like COVID-19 has also highlighted the need for telerehab services [2] to support both patients and clinicians by reducing the burden on health care and the hectic routine, lethargy, and expenditure of moving while enhancing regularity and consistency in patient's follow-ups [11]. In far-flung, remote areas, the scarcity of rehabilitation facilities, especially the SLP services, is considered challenging due to the cost involved in commuting and the need for regular follow-ups for better results as well [12]. Hence SLP services are essentially required to deliver correctional and developmental therapies by taking advantage of informational and communicational technology for accompanying and supporting, especially youngsters and their parents with disorders of speech in remote areas [13]. Telepractice can be of 
use in different age groups from infants to adulthood for various speech, hearing, behavioral, and communicational issues, including disorders of voice, articulation, aphasia, dysarthria, and speech sound errors. Also, the provision of coaching and teaching services by SLP's to parents of children with communicational issues to bring improvement in their children [14]. This practice assures delivering the SLPs' services to the remote areas in Pakistan, where it is a relatively new specialty.

With the delimitation of information technology from desktops to laptops, smartphones with cellular packages, access to SLP services has become very easy for the majority living in remote areas [14]. This service can be provided by even low-cost or accessible video communication applications like Apple FaceTime, Skype, Google Hangouts, etc. [15]. However, some infrastructural improvements in connection with the privacy and security of data and clients, training of SLPs, and policies would be required [16]. There is enhancing affirmation that telepractice is as essential a tool even in difficult to treat conditions like stuttering as conventional face-toface therapy and requires further research [17].

With a comparatively novel area for research, primarily because of the COVID-19 pandemic and particularly with the scarcity of research in the field of SLPs, especially telepractice, It is obligatory to facilitate the improvised patients by overcoming the barriers such as lack of resources and long distances in the remote areas, especially in developing countries [18]. Thus, the current study was conducted to explore the satisfaction and competency of telepractice services among SLPs in Pakistan. The current study will help to analyze the accessibility and service quality of SLPs, particularly for those patients who are living in remote areas and need therapy services for communication and feeding and swallowing disorders but cannot access the services because of long distances, logistics, or other pertinent reasons. This population can benefit from speech-language therapy (SLT) services through teletherapy sessions along with significant others in the geriatric population facing SpeechLanguage Disorders (SLDs) with compromised mobility as well. It can address a significant gap of research for the provision of SLT services in society.

\section{Materials and Methods}

This cross-sectional study was conducted at Riphah International University, Lahore, Pakistan, from August 1, 2020, to December 31, 2020, for 5 months. A sample of 204 SLPs working in different public and private centers in Pakistan were recruited using the convenience sampling method. The number of 240 SLPs was calculated using Solvin's formula $(n=N / 1+N e 2)$ with a population size of 600 , a margin of error of $5 \%$, and a confidence interval of $95 \%$. The sample included qualified SLPs of both genders, aged between 25-60 years. Non-practicing SLPs and those holding administrative posts or with incomplete returned questionnaires were excluded from the study.

We used The "Service Provider Questionnaire for Telepractice" developed by Akamoglu et al. [19] to assess service delivery by SLPs using telepractice, including rapport building with families (both parents and children), for data collection; however, it lacks validity and reliability. This questionnaire comprises 20 questions, out of which 12 related to demographic information, 2 to advantages and disadvantages of telepractice, and 6 assess the satisfaction and competency rating about delivering services via telepractice. Satisfaction is rated as very satisfied, satisfied, neutral, dissatisfied, to very dissatisfied. Besides, competence is rated as highly competent, competent, somewhat competent, and not competent, and frequency of responses is noted, too.

The study was conducted after obtaining ethical approval from the Ethics Review Committee of Riphah International University, Lahore, vide registration number REC/RCRS/20/3018 dated August 1, 2020. The informed consent was taken from the sample who were qualified, practicing SLPs, of both genders, aged 25-60 years and working in different public and private centers in Pakistan. The questionnaire for teletherapy practice was shared with the sample population using e-mail, and the returned completed questionnaire was added to the data after thorough scrutiny. Cases with incomplete data were excluded from the study leaving behind 204 samples used for data analysis in SPSS v. 22. Descriptive statistics and the Chi-square and Pearson $r$ correlation were used to see associations with age, qualification, and experience. $P$ values equal to or less than 0.05 were considered significant. Results were then compared with both local and international literature and discussed.

\section{Results}

Demographic characteristics of the sample population are presented in Table 1. Satisfaction with telepractice compared to face-to-face practice did not reveal a significant difference with a very weak negative correlation $(\mathrm{r}=-0.102, \mathrm{P}=0.146)$, though the majority, i.e., 124 were very satisfied, and 67 were satisfied with face-to-face practice compared to 106 satisfied and 4 very satisfied with telepractice (Table 2A). 
Table 1. Demographic characteristics of the study participants (N=204)

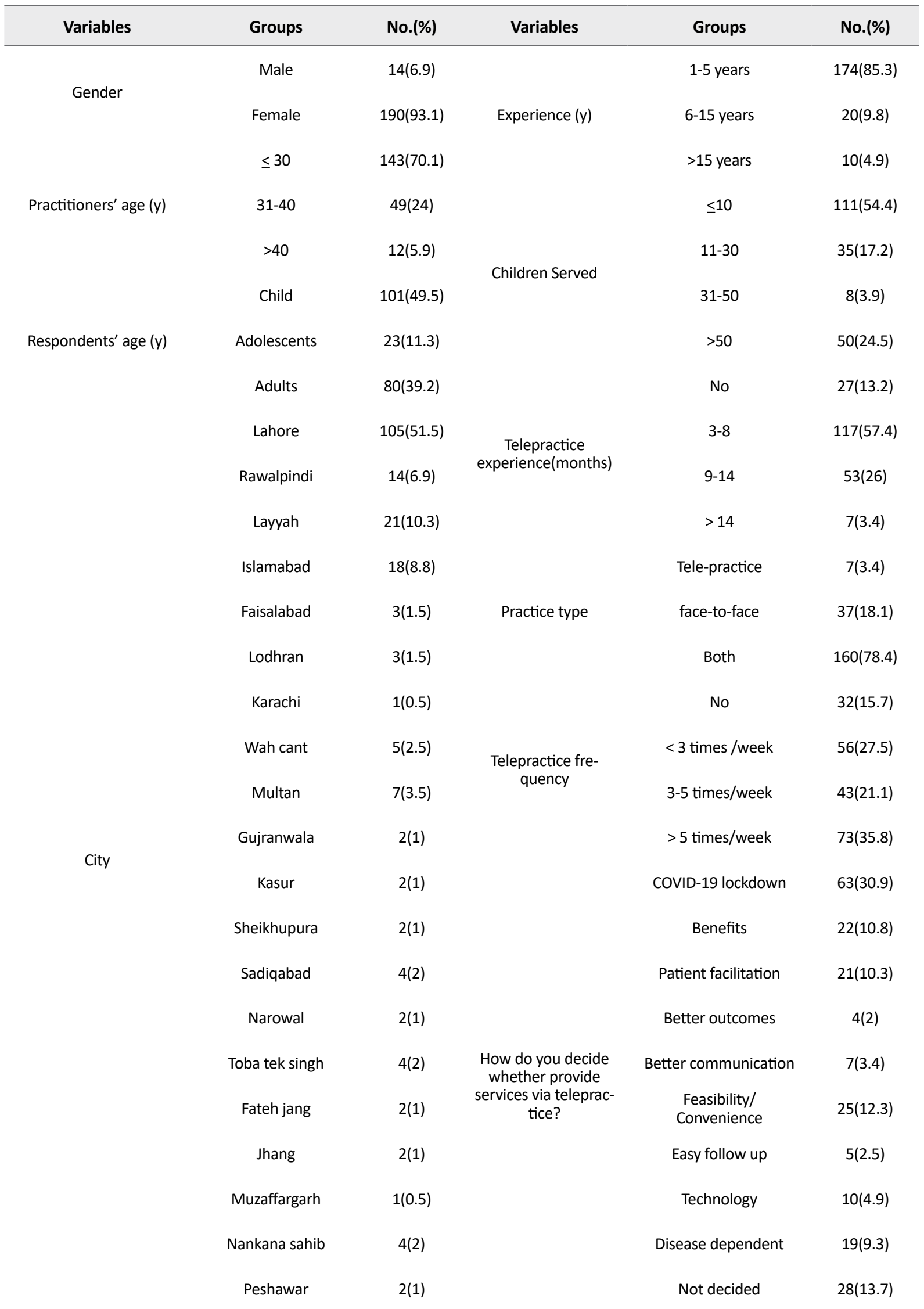




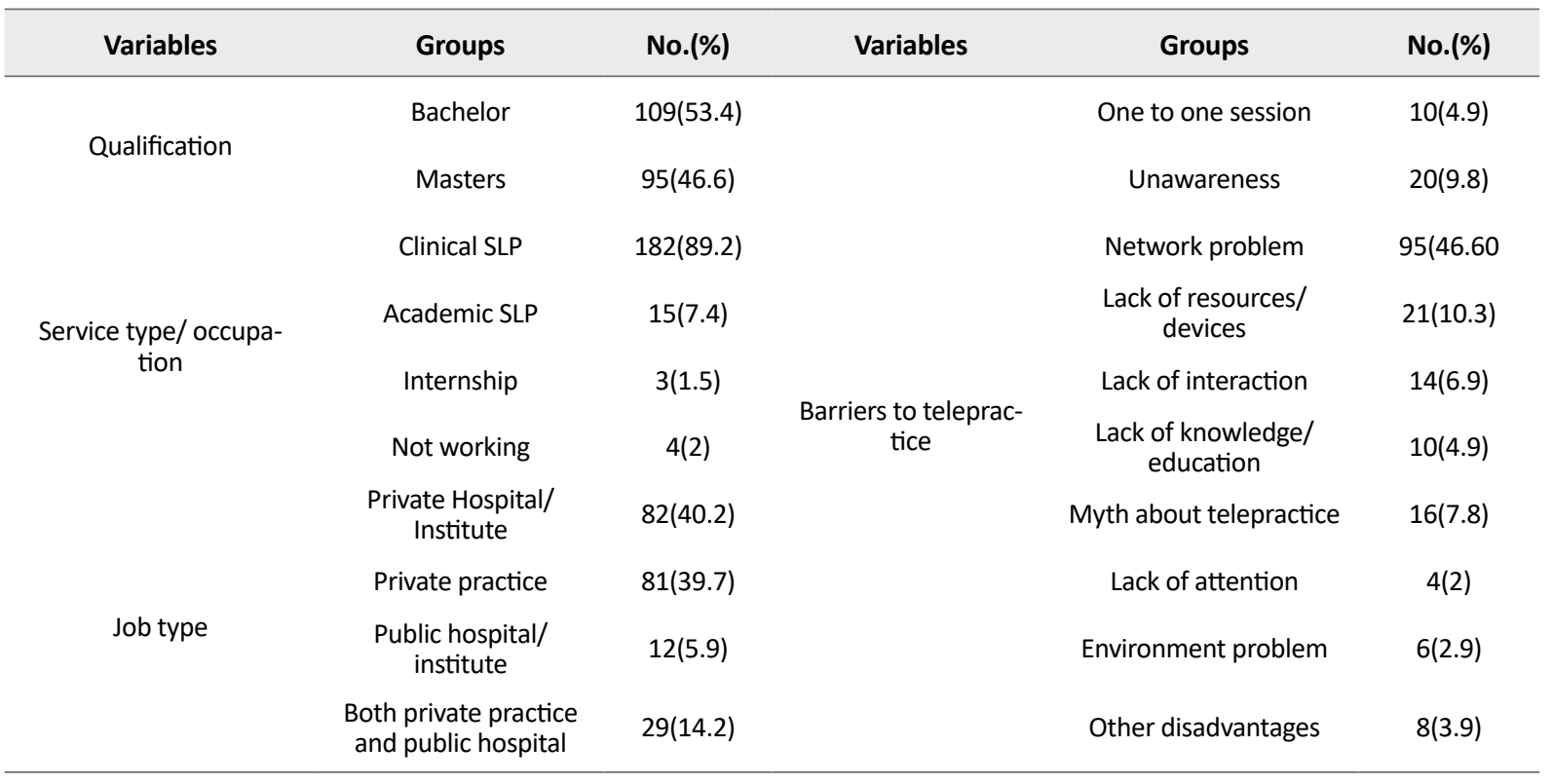

Iranian Rehabilitation Journa

On the other hand, regarding building a relationship with child/family, most SLPs, nearly 125 people, were very satisfied and 70 satisfied using face-to-face practice, while 119 were satisfied and 12 very satisfied with telepractice. However, the difference was not significant, with a very weak positive correlation $(\mathrm{r}=0.01, \mathrm{P}=0.882)$ (Table 2B).

As far as competence in providing services is concerned, 118 SLPs felt competent, and only 22 highly competent with telepractice, while 113 felt highly competent and 82 competent with face-to-face practice, and the difference was statistically significant with a very weak positive correlation ( $\mathrm{r}=0.165, \mathrm{P}=0.018$ ) (Table 2C).

A statistically significant association of satisfaction using telepractice was noted with the age group of patients $(\mathrm{P}=0.042)$, the experience of SLPs $(\mathrm{P}=0.002)$, and the age of SLP (0.049). Also, a significant association of satisfaction using face-to-face practice was noted with experience $(\mathrm{P}=0.003)$ and age of SLP $(\mathrm{P}=0.005)$ (Table $3 \mathrm{~A})$.

Regarding the satisfaction with building a relationship with child/family using telepractice, it has a significant association with SLPs' qualification $(\mathrm{P}=0.002)$ and experience $(\mathrm{P}=0.015)$, while in the case of face-to-face practice, it had a statistically significant association with SLP's experience $(\mathrm{P}=0.043)$ and age $(\mathrm{P}=0.04)$ (Table 3B).

Also, competence in providing telepractice service is significantly associated with patients' age group ( $\mathrm{P}=0.029)$, SLP's qualification $(\mathrm{P}<0.001)$, experience
$(\mathrm{P}=0.001)$, and age $(\mathrm{P}=0.01)$, while for face-to-face practice, no significant association was noted (Table 3C).

\section{Discussion}

The current study involved 204 qualified SLPs, with a majority of them being females, less than 30 years old (70\%) with $1-5$ years of experience $(n=85.3)$ because speech-language pathology is a relatively new field in Pakistan, where institutions awarding a degree in SLP mushroomed in recent years. Hence most SLPs (53.4\%) hold bachelor's degrees and work as clinical SLPs in private settings. Most SLPs were satisfied with telepractice, and a majority felt competent. Similarly, Balliette reported that $50 \%$ of service providers, as well as $45 \%$ of patients, gave a positive response of going through telepractice [20]. Tucker surveyed 170 SLPs. He found that the rate of telepractice use was just $1.8 \%$ in a school setting [21]. While in the current study, 3.4\% were using telepractice alone, and a very large figure of $78.4 \%$ used both telepractice and face-to-face practice.

While exploring the satisfaction and competency of SLP's with telepractice services in Pakistan, the present study revealed that SLPs were very satisfied and competent in providing services and relationship building with child/family via telepractice. However, they were more satisfied and highly competent in providing services and relationship building with child/family via face-to-face therapy services. Similarly, Sharma et al. reported that patients' comfort regarding using telepractice was over $80 \%$ with $>90 \%$ perceived general benefit with telepractice; however, $45 \%$ preferred face-to-face assessment 
Table 2. Satisfaction and competence using telepractice versus face-to-face, cross tabulation with pearson $r$ correlation $(n=204)$

\begin{tabular}{|c|c|c|c|c|c|c|c|}
\hline A & \multicolumn{6}{|c|}{ Please rate your satisfaction with providing services in person, face-to-face? } & \multirow{2}{*}{$\begin{array}{c}\begin{array}{c}\text { Pearson } \\
\text { correlation }\end{array} \\
\mathrm{r} / \mathrm{P}\end{array}$} \\
\hline Satisfaction & Response & $\begin{array}{l}\text { Very Dis- } \\
\text { satisfied }\end{array}$ & Neutral & Satisfied & Very Satisfied & Total & \\
\hline \multirow{6}{*}{  } & Very dissatisfied & . & 0 & 0 & 2 & 2 & \\
\hline & Dissatisfied & . & 1 & 10 & 18 & 29 & \\
\hline & Neutral & & 10 & 6 & 47 & 63 & $\begin{array}{l}-0.102 \\
0.146\end{array}$ \\
\hline & Satisfied & & 2 & 47 & 57 & 106 & \\
\hline & Very satisfied & . & 0 & 4 & 0 & 4 & \\
\hline & Total & & 13 & 67 & 124 & 204 & \\
\hline
\end{tabular}

Mranian Rehabilitation Dournal

\begin{tabular}{cccccccc}
\hline \multicolumn{6}{c}{ B } & \multicolumn{7}{c}{$\begin{array}{c}\text { Please rate your satisfaction with the relationships you have with the child/family when provid- } \\
\text { ing services in person, face-to-face? }\end{array}$} \\
\hline & Response & Very dissatisfied & Neutral & Satisfied & Very satisfied & Total \\
\hline & Very dissatisfied & 0 & 0 & 2 & 2 & 4 \\
\hline
\end{tabular}

\begin{tabular}{|c|c|c|c|c|c|c|}
\hline \multirow[t]{2}{*}{ C Competence } & \multicolumn{5}{|c|}{ Please rate your competence in providing services in person, face-to-face? } & \\
\hline & Response & Competent & Somewhat competent & Highly competent & Total & \\
\hline \multirow{5}{*}{ 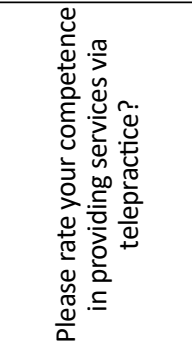 } & Not competent & 9 & 0 & 6 & 15 & \multirow{5}{*}{$\begin{array}{l}0.165 \\
0.018\end{array}$} \\
\hline & Competent & 51 & 6 & 61 & 118 & \\
\hline & $\begin{array}{l}\text { Somewhat } \\
\text { competent }\end{array}$ & 16 & 3 & 30 & 49 & \\
\hline & $\begin{array}{l}\text { Highly compe- } \\
\text { tent }\end{array}$ & 6 & 0 & 16 & 22 & \\
\hline & Total & 82 & 9 & 113 & 204 & \\
\hline
\end{tabular}

Iranian Rehabilitation \ournal

$\mathrm{r}$ values greater than 0.50 indicate a strong correlation, $r$ values around 0.30 shows moderate correlation, and $r$ values less than 0.20 indicate a weak correlation.

** Correlation is significant at the 0.01 level (2-tailed).

[22]. According to Murphy et al., it is essential to build a satisfactory rapport with family/child by the SLP for gaining best results in telepractice [23], and for this objective, the therapist should use physical material plus e-material and keep hands on for the best performance of the child and enhancing therapist's competence [24].
Though SLPs were more satisfied with face-to-face practice, satisfaction with telepractice compared to face-to-face practice revealed no significant difference. Similarly, as regards satisfaction with building relationships with child/family, no significant association was noted. In contrast to our study, Grogan-Johnson et al. argued that telepractice was not suitable with children 
Table 3. Demographic variables versus satisfaction and competence using telepractice and face-to-face, cross tabulation and the Chi-Square association $(n=204)$

\begin{tabular}{|c|c|c|c|c|c|c|c|c|c|c|c|c|c|}
\hline \multirow[b]{3}{*}{ A) Variables } & \multirow[b]{3}{*}{ Groups } & \multicolumn{12}{|c|}{ Please rate Your Satisfaction to Provide Services Using } \\
\hline & & \multicolumn{6}{|c|}{ Telepractice } & \multicolumn{6}{|c|}{ In-Person Face-to-Face } \\
\hline & & 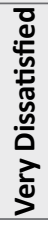 & 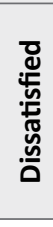 & $\begin{array}{l}\bar{\pi} \\
\frac{\pi}{3} \\
\frac{0}{2}\end{array}$ & 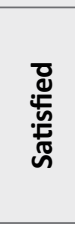 & 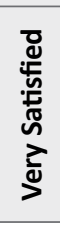 & $\stackrel{0}{x}$ & 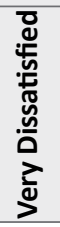 & 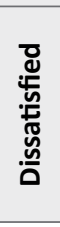 & 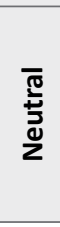 & 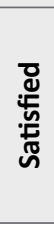 & 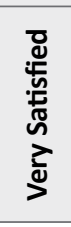 & $\dot{x}$ \\
\hline \multirow{3}{*}{$\begin{array}{l}\text { Age groups } \\
\text { of patient }\end{array}$} & Child (101) & 0 & 10 & 25 & 64 & 2 & \multirow{3}{*}{$\begin{array}{l}15.995 \\
0.042\end{array}$} & 0 & 0 & 5 & 32 & 64 & \multirow{3}{*}{$\begin{array}{l}4.12 \\
0.404\end{array}$} \\
\hline & $\begin{array}{l}\text { Adolescents } \\
\quad(23)\end{array}$ & 0 & 3 & 11 & 8 & 1 & & 0 & 0 & 0 & 9 & 14 & \\
\hline & Adults (80) & 2 & 16 & 27 & 34 & 1 & & 0 & 0 & 8 & 26 & 46 & \\
\hline \multirow{2}{*}{ Qualification } & BS Hons (109) & 2 & 10 & 30 & 65 & 2 & \multirow{2}{*}{$\begin{array}{l}9.454 \\
0.051\end{array}$} & 0 & 0 & 11 & 36 & 62 & \multirow{2}{*}{$\begin{array}{l}5.67 \\
0.059\end{array}$} \\
\hline & MS-SLP (95) & 0 & 19 & 33 & 41 & 2 & & 0 & 0 & 2 & 31 & 62 & \\
\hline \multirow{3}{*}{ Experience } & $1-5$ years $(174)$ & 0 & 25 & 49 & 96 & 4 & \multirow{3}{*}{$\begin{array}{l}24.85 \\
0.002\end{array}$} & 0 & 0 & 13 & 65 & 96 & \multirow{3}{*}{$\begin{array}{c}16.022 \\
0.003\end{array}$} \\
\hline & $6-15$ years $(20)$ & 2 & 2 & 9 & 7 & 0 & & 0 & 0 & 0 & 2 & 18 & \\
\hline & $>15$ years $(10)$ & 0 & 2 & 5 & 3 & 0 & & 0 & 0 & 0 & 0 & 10 & \\
\hline \multirow{3}{*}{$\begin{array}{l}\text { Age group } \\
\text { of SLP (y) }\end{array}$} & $\leq 30(143$ & 0 & 18 & 41 & 82 & 2 & \multirow{3}{*}{$\begin{array}{l}15.241 \\
0.049\end{array}$} & 0 & 0 & 13 & 52 & 78 & \multirow{3}{*}{$\begin{array}{c}14.649 \\
0.005\end{array}$} \\
\hline & $31-40$ (49) & 2 & 9 & 15 & 21 & 2 & & 0 & 0 & 0 & 15 & 34 & \\
\hline & $40(12)$ & 0 & 2 & 7 & 3 & 0 & & 0 & 0 & 0 & 0 & 12 & \\
\hline Total & 204 & 2 & 29 & 63 & 106 & 4 & & 0 & 0 & 13 & 67 & 124 & \\
\hline \multirow{2}{*}{ B) Variables } & Groups & \multicolumn{12}{|c|}{$\begin{array}{l}\text { Please rate your satisfaction with the relationships you have with the child/family while } \\
\text { providing service using }\end{array}$} \\
\hline & & \multicolumn{6}{|c|}{ Telepractice } & \multicolumn{6}{|c|}{ In-Person Face-to-Face } \\
\hline \multirow{3}{*}{ Age groups } & Child (101) & 2 & 7 & 17 & 70 & 5 & & 1 & 0 & 3 & 40 & 57 & \multirow{3}{*}{$\begin{array}{l}6.852 \\
0.335\end{array}$} \\
\hline & $\begin{array}{l}\text { Adolescents } \\
\quad(23)\end{array}$ & 0 & 2 & 8 & 12 & 1 & $\begin{array}{c}11.803 \\
0.16\end{array}$ & 0 & 0 & 0 & 5 & 18 & \\
\hline & Adults (80) & 2 & 8 & 27 & 37 & 6 & & 0 & 0 & 5 & 25 & 50 & \\
\hline \multirow{2}{*}{ Qualification } & BS Hons (109) & 4 & 5 & 19 & 73 & 8 & \multirow{2}{*}{$\begin{array}{c}17.231 \\
0.002\end{array}$} & 1 & 0 & 6 & 41 & 61 & \multirow{2}{*}{$\begin{array}{l}4.188 \\
0.242\end{array}$} \\
\hline & MS-SLP (95) & 0 & 12 & 33 & 46 & 4 & & 0 & 0 & 2 & 29 & 64 & \\
\hline \multirow{3}{*}{ Experience } & $1-5$ years $(174)$ & 2 & 17 & 41 & 104 & 10 & & 1 & 0 & 8 & 67 & 98 & \multirow{3}{*}{$\begin{array}{l}13.03 \\
0.043\end{array}$} \\
\hline & $6-15$ years $(20)$ & 2 & 0 & 9 & 9 & 0 & $\begin{array}{c}18.908 \\
0.015\end{array}$ & 0 & 0 & 0 & 3 & 17 & \\
\hline & $>15$ years $(10)$ & 0 & 0 & 2 & 6 & 2 & & 0 & 0 & 0 & 0 & 10 & \\
\hline & $\leq 30(143$ & 2 & 12 & 31 & 90 & 8 & & 1 & 0 & 8 & 55 & 79 & \\
\hline $\begin{array}{l}\text { Age group } \\
\text { of SLP }\end{array}$ & $31-40$ (49) & 2 & 5 & 17 & 23 & 2 & 9.945 & 0 & 0 & 0 & 15 & 34 & 13.181 \\
\hline & $40(12)$ & 0 & 0 & 4 & 6 & 2 & 0.269 & 0 & 0 & 0 & 0 & 12 & 0.04 \\
\hline Total & 204 & 4 & 17 & 52 & 119 & 12 & & 1 & 0 & 8 & 70 & 125 & \\
\hline
\end{tabular}




\begin{tabular}{|c|c|c|c|c|c|c|c|c|c|c|c|}
\hline \multirow[b]{3}{*}{ C) Variables } & \multirow[b]{3}{*}{ Groups } & \multicolumn{10}{|c|}{ Please Rate Your Competence in Providing Services Via: } \\
\hline & & \multicolumn{5}{|c|}{ Telepractice } & \multicolumn{5}{|c|}{ In-Person Face-to-Face } \\
\hline & & 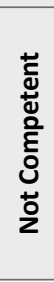 & 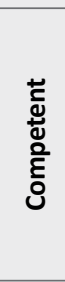 & 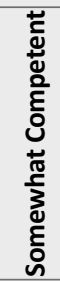 & 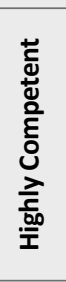 & & 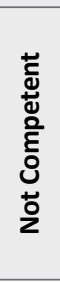 & 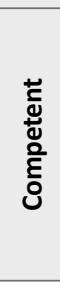 & 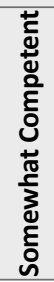 & 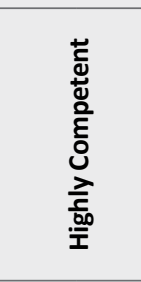 & \\
\hline \multirow{3}{*}{ Age groups } & Child (101) & 4 & 69 & 18 & 10 & \multirow{3}{*}{$\begin{array}{c}14.028 \\
0.029\end{array}$} & 0 & 42 & 2 & 57 & \\
\hline & $\begin{array}{l}\text { Adolescents } \\
\text { (23) }\end{array}$ & 1 & 13 & 8 & 1 & & 0 & 6 & 3 & 14 & $\begin{array}{l}6.859 \\
0.144\end{array}$ \\
\hline & Adults (80) & 10 & 36 & 23 & 11 & & 0 & 34 & 4 & 42 & \\
\hline \multirow{2}{*}{ Qualification } & BS Hons (109) & 9 & 74 & 13 & 13 & \multirow{2}{*}{$\begin{array}{c}18.878 \\
0.000\end{array}$} & 0 & 52 & 4 & 53 & 5.512 \\
\hline & MS-SLP (95) & 6 & 44 & 36 & 9 & & 0 & 30 & 5 & 60 & 0.064 \\
\hline \multirow{3}{*}{ Experience } & $1-5$ years (174) & 15 & 104 & 36 & 19 & \multirow{3}{*}{$\begin{array}{l}17.82 \\
0.007\end{array}$} & 0 & 72 & 9 & 93 & \multirow{3}{*}{$\begin{array}{l}3.916 \\
0.418\end{array}$} \\
\hline & $6-15$ years $(20)$ & 0 & 9 & 11 & 0 & & 0 & 8 & 0 & 12 & \\
\hline & $>15$ years $(10)$ & 0 & 5 & 2 & 3 & & 0 & 2 & 0 & 8 & \\
\hline \multirow{3}{*}{$\begin{array}{l}\text { Age group of } \\
\text { SLP }\end{array}$} & $\leq 30(143$ & 14 & 89 & 25 & 15 & & 0 & 64 & 6 & 73 & \multirow[b]{3}{*}{$\begin{array}{l}6.435 \\
0.169\end{array}$} \\
\hline & $31-40$ (49) & 1 & 24 & 20 & 4 & & 0 & 16 & 3 & 30 & \\
\hline & $40(12)$ & 0 & 5 & 4 & 3 & $\begin{array}{c}16.909 \\
0 . .01\end{array}$ & 0 & 2 & 0 & 10 & \\
\hline Total & 204 & 15 & 118 & 49 & 22 & & 0 & 82 & 9 & 113 & \\
\hline
\end{tabular}

Mranian Rehabilitation Journa

for speech-related disorders [25] since lack of proximity and closeness is an issue in building relationships with clients because a child suffering from behavioral issues cannot develop a suitable affiliation with the SLPs [26]. Akamoglu Y et al. also emphasized rapport-building activities for telepractice to be beneficial [19].

As far as competence in providing services is concerned, we found that many SLPs felt competent with face-toface practice compared to telepractice, and the difference was statistically significant, though telepractice service is a feasible means of providing SLP services [16].

Regarding factors associated with satisfaction with telepractice, the current study revealed an association with the patient's age. However, according to GroganJohnson et al., it was not suitable for children [25]. Balliette reported no relationship of participants' age with the desire to participate in telepractice [20]. But in another study, willingness to use telepractice was inversely correlated with age, indicating that the younger population is more apt towards technology [21].

In this study, the satisfaction and competence in providing telepractice was significantly associated with the younger age of SLPs while in the case of face-to-face practice, satisfaction was significantly associated with the age group of SLP, while competence was not associated wcompetent and satisfied, while in the case of face-to-face practice, satisfaction with practice and satisfaction with relationships was significantly associated with the age group of SLP, while competence was not associated with SLP's age.

Also, the current study revealed an association of satisfaction with relationship building with child/family using telepractice and face-to-face practice with the experience of SLPs. Also, Orlando et al. reported the association of telepractice with experience [27]. 
In the present study, satisfaction with building relationships with child/family using telepractice also revealed an association with the qualification of SLPs. Hence, a postgraduate qualification in speech pathology is essentially required to deliver telepractice [16].

In the current study, we found that competence in providing telepractice service is significantly associated with patient's age as younger age is associated with better competence. Similarly SLPs' with Bachelor's qualification revealed better competence as in another study by Mohan et al. [16]. Competence in providing telepractice was also significantly associated with the experience of SLPs with 1-5 years of experience. Orlando et al. also reported this association with experience [27]. Association of competence in providing telepractice with lower age group, qualification \& experience may be due to the fact that younger population is more adapted to using information technology in daily life. In the current study, the face-to-face practice was not associated with age, qualification, or experience. In contrast, the nonsuitability of telepractice has been reported for children [25].

Ashburner J et al. reported that in the treatment of autistic children, despite disappointment due to technical issues, participants supported telepractice [28], indicating that benefits outweigh the barriers. Similarly, in the current study, technical issues like network problems, lack of resources/devices were the main barriers to telepractice in $46.6 \%$ and $10.3 \%$ of cases, respectively. Gabel M et al. suggested that telepractice and face-to-face practice are somewhat similar and hence telepractice was a viable option [29]. Hence telepractice has a lot of clinical implications in SLP, being useful for far-flung areas with a dearth of SLPs for most therapies for children and adults and counseling and guidance of parents. Thus, it is advisable to make the SLP service accessible for the whole population [15], especially in developing countries, without discrimination.

\section{Study limitations}

Due to the prevailing COVID-19 pandemic and internet issues, data collection has faced some difficulties. Also, SLP is a comparatively new field in Pakistan, and most SLPs in this study were young with experience of 1-5 years. Finally, "Service Provider Questionnaire for Telepractice" lacks validity and reliability.

\section{Conclusion}

SLPs are pretty satisfied with using telepractice and relationship building with child/family, and the results did not differ significantly from face-to-face practice. However for competence in providing services, the SLPs felt more skilled with face-to-face practice than telepractice. Satisfaction in using telepractice is associated with patient's age and SLP's experience and age, while satisfaction with relationships using telepractice has an association with qualification and experience. Competence in providing telepractice is associated with the patient's age and SLP's qualification, experience, and age. However, further research is recommended for each speech-language disorder and incorporation of feasible virtual reality treatment.

\section{Ethical Considerations}

\section{Compliance with ethical guidelines}

This study was approved by the Ethics Review Committee Riphah International University, Lahore, Pakistan vide Reg\#REC/RCRC/20/3018.

\section{Funding}

The paper was extracted from the MSc. thesis of the first author at the Department of SLP, Riphah International University, Lahore, Pakistan.

\section{Authors' contributions}

Conceptualization and supervision: Nazia Mumtaz, Nameeka Shahid; Methodology, resources \& data curation: Sidra Akram, Nameeka Shahid; Formal analysis and writing - original draft preparation: Ghulam Saqulain, Sidra Akram; Writing - review \& editing and Supervision: Ghulam Saqulain, Nazia Mumtaz.

\section{Conflict of interest}

The authors declared no conflict of interest.

\section{References}

[1] Mumtaz N, Saqulain G, Mumtaz N. Online academics in Pakistan: COVID-19 and beyond. Pakistan Journal of Medical Sciences. 2021; 37(1):283-7. [DOI:10.12669/pjms.37.1.2894] [PMID] [PMCID]

[2] Mumtaz N, Saqulain G, Mumtaz N. COVID-19 rehab fright management. Pakistan Journal of Medical Science. 2021; 37(1):277-82. [DOI:10.12669/pjms.37.1.3187] [PMID] [PMCID]

[3] Juenger JM. Telepractice in the schools: Virtual services help clinicians do more with less. The ASHA Leader. 2009; 14(12):20-1. [DOI:10.1044/leader.FTR2.14122009.20] 
[4] Behl DD, Kahn G. Provider perspectives on telepractice for serving families of children who are deaf or hard of hearing. International Journal of Telerehabilitation. 2015; 7(1):1-12. [DOI:10.5195/ijt.2015.6170] [PMID] [PMCID]

[5] Denton DR, Gladstone VS. Ethical and legal issues related to telepractice. Seminars in Speech and Language. 2005; 26(1):43-52. [DOI:10.1055/s-2005-863794]

[6] Roy N, Barkmeier-Kraemer J, Eadie T, Sivasankar MP, Mehta D, Paul D, et al. Evidence-based clinical voice assessment: A systematic review. American Journal of SpeechLanguage Pathology. 2013; 22(2):212-26. [DOI:10.1044/10580360(2012/12-0014)]

[7] McCullough A. Viability and effectiveness of teletherapy for pre-school children with special needs. International Journal of Language \& Communication Disorders. 2001; 36(Suppl):321-6. [DOI:10.3109/13682820109177905] [PMID]

[8] Brown J. The State of Telepractice in 2014: Telepractice is an ever-expanding service-delivery option, with more US speech-language pathologists and audiologists adopting it every day. But reimbursement policies continue to lag behind the trend. The ASHA Leader. 2014; 19(12):54-7. [DOI:10.1044/ leader.FTR3.19122014.54]

[9] Cason J, Cohn ER. Telepractice: An overview and best practices. The ASHA Leader. 2014; 23(1):4-17. [DOI:10.1044/ aac23.1.4]

[10] Polovoy C. Telepractice in schools helps address personnel shortages. The ASHA Leader. 2008; 13(9):22-4. [DOI:10.1044/ leader.FTR3.13092008.22]

[11] Freckmann A, Hines M, Lincoln M. Clinicians' perspectives of therapeutic alliance in face-to-face and telepractice speech-language pathology sessions. International Journal of Speech-Language Pathology. 2017; 19(3):287-96 [DOI:10.1080 /17549507.2017.1292547] [PMID]

[12] Brennan DM, Tindall L, Theodoros D, Brown J, Campbell $\mathrm{M}$, Christiana D et al. A blueprint for telerehabilitation guidelines--October 2010. Telemedicine Journal and E-Health. 2011; 17(8):662-5 [DOI:10.1089/tmj.2011.0036] [PMID]

[13] Mytsyk A, Pryshliak M. Telepractice in the system of providing correctional and developmental services to children with speech disorders: interaction at a distance. Journal of History Culture and Art Research. 2020; 9(3):94-105 [DOI:10.7596/taksad.v9i3.2674]

[14] Snodgrass MR, Chung MY, Biller MF, Appel KE, Meadan $\mathrm{H}$, Halle JW. Telepractice in speech-language therapy: The use of online technologies for parent training and coaching. Communication Disorders Quarterly. 2017; 38(4):242-54. [DOI:10.1177/1525740116680424]

[15] Rabanifar N, Abdi K. Telerehabilitation: A useful and appropriate approach for people with disability in COVID 19 pandemic. Medical Journal of the Islamic Republic of Iran. 2021; 35:18. [DOI:10.47176/mjiri.35.18] [PMID] [PMCID]

[16] Mohan HS, Anjum A, Rao PKS. A survey of telepractice in speech-language pathology and audiology in India. International Journal of Telerehabilitation. 2017; 9(2):69-80 [DOI:10.5195/ijt.2017.6233] [PMID] [PMCID]

[17] O'Brian S , Smith K , Onslow M. Webcam Delivery of the lidcombe program for early stuttering: A phase I clinical trial.
Journal of Speech, Language, and Hearing Research. 2014; 57(3):825-30. [DOI:10.1044/2014_JSLHR-S-13-0094] [PMID]

[18] Rabanifar N, Abdi K. Rehabilitation services: Why should we use tele-rehabilitation in Iran? Necessity and Application. Iranian Rehabilitation Journal. 2019; 17(4):293-6. [DOI:10.32598/irj.17.4.293]

[19] Akamoglu Y, Meadan H, Pearson JN, Cummings K. Getting connected: Speech and language pathologists' perceptions of building rapport via telepractice. Journal of Developmental and Physical Disabilities. 2018; 30(4):569-85 [DOI:10.1007/s10882-018-9603-3]

[20] Balliette C. The Use of and readiness for speech-language telepractice in medical settings of rural areas of Nevada [Msc thesis]. Bowling Green: Western Kentuckty University; 2016. http://digitalcommons.wku.edu/theses/1571

[21] Tucker JK. Perspectives of speech-language pathologists on the use of telepractice in schools: Quantitative survey results. International Journal of Telerehabilitation. 2012; 4(2):61-72. [DOI:10.5195/ijt.2012.6100] [PMID] [PMCID]

[22] Sharma S, Ward EC, Burns C, Theodoros D, Russell T. Assessing dysphagia via telerehabilitation: Patient perceptions and satisfaction. International Journal of Speech-Language Pathology. 2013; 15(2):176-83. [DOI:10.3109/17549507.2012.6 89333] [PMID]

[23] Murphy E, Rodríguez-Manzanares MA. Rapport in distance education. The Internatiobal Review of Research in Oppen and Distributed Learning. 2012; 13(1):167-90 [DOI:10.19173/irrodl.v13i1.1057]

[24] Hines M, Lincoln M, Ramsden R, Martinovich J, Fairweather C. Speech pathologists' perspectives on transitioning to telepractice: What factors promote acceptance? Journal of Telemedicine and Telecare. 2015; 21(8):469-73. [DOI:10.1177/1357633X15604555] [PMID]

[25] Grogan-Johnson S, Schmidt AM, Schenker J, Alvares R, Rowan LE, Taylor J. A comparison of speech sound intervention delivered by telepractice and side-by-side service delivery models. Communication Disorders Quarterly. 2013; 34(4):210-20. [DOI:10.1177/1525740113484965]

[26] Anderson K, Balandin S, Stancliffe RJ, Layfield C. Parents' perspectives on tele-AAC support for families with a new speech generating device: Results from an Australian pilot study. Perspectives on Telepractice. 2014; 4(2):52-60. [DOI:10.1044/teles4.2.52]

[27] Orlando JF, Beard M, Kumar S. Systematic review of patient and caregivers' satisfaction with telehealth videoconferencing as a mode of service delivery in managing patients' health. PLoS ONE. 2019; 14(8):e0221848. [DOI:10.1371/journal.pone.0221848] [PMID] [PMCID]

[28] Ashburner J, Vickerstaff S, Beetge J, Copley J. Remote versus face-to-face delivery of early intervention programs for children with autism spectrum disorders: Perceptions of rural families and service providers. Research in Autism Spectrum Disorders. 2016; 23:1-4. [DOI:10.1016/j.rasd.2015.11.011]

[29] Gael R, Grogan-Johnson S, Alvares R, Bechstein L, Taylor $\mathrm{J}$. A field study of telepractice for school intervention using the ASHA NOMS K-12 Database. Communication Disorders Quarterly. 2013;35(1):44-53. [DOI:10.1177/1525740113503035] 